\section{Child health services in the community: making them work}

Britain's community child health services are in confusionprimarily in terms of the provision of services. As a result, the health professionals concerned have become demoralised, and this is reflected in the bickering among their representative organisations.

A survey in 1983 found that each of the 192 health districts in England seems to run its own totally different child health surveillance programme. The choice seems to depend more on the whim of the individuals responsible than on any apparent rationale such as research. ${ }^{1}$ Some districts run five times as many child health clinics (corrrected for numbers of children in their preschool population) than others-but not (apparently) as a result of any objective assessment of factors such as degree of urbanisation, percentage immigrant population, rates of unemployment, incidence of social class VI or $\mathrm{V}$ families, or evidence of increased benefits for the children.

Another recently published report-by the Comptroller and Auditor General-showed that in 198323 districts had an uptake of whooping cough vaccine of less than half, while in 1984 the national overall uptake was only two thirds. A total of 94000 cases of measles were reported in England and Wales in 1982, when in the whole of the United States only 1697 were reported in the same year.

Why is there this disorganisation? There must be many reasons-partly historical, partly because the services are administered in each of the districts by an extraordinarily wide variety of individuals (district medical officers, community physicians, senior or principal medical officers, community paediatricians, and pure administrators) with totally different training, and partly because there is so little research (especially population based research) on which to base a logical programme.

No parent will find it reasonable to have different schedules and advice given about immunisations when moving from one health district to another. Nor will it seem reasonable that in each district the hearing test may be done differently - or that a child may miss it altogether because in some districts it is performed at the age of 9 months and in others at 8 months. In some districts the Denver development screening test is used as a screening instrument and an hour or so over the child's lifetime is spent filling it in-while the same districts' immunisation policies may leave over a quarter of all children unimmunised against whooping cough and measles.

The community child health services include clinical work, teaching, a little research (far too little), and much administration. The clinical element alone has many different elements, two of which are child health surveillance and the management and treatment of children with special needs. The basis of child health surveillance rests on immunisations, screening, assessment, and giving advice and reassurance.

Having damned our national record, I would recant somewhat and say that there is some hope. After years of indecision and conflicting information, mainly based on totally inadequate research, the DHSS and others have recently funded some good studies and there are now clear national guidelines at least for immunisation policies. Thus we now have national target figures for the uptake of certain immunisations, and every district's immunisation figures are available with the recently introduced performance indica- tors. These seem to show a steady upwards trend in the uptake of pertussis and measles vaccines-a trend whicl could be rapidly increased if we chose to follow the Americar? system, by which completion of the primary immunisation courses is virtually mandatory for entry into school. Nows that we have these excellent guidelines and target rates for the uptake of immunisations, could not this initiative be exक tended to screening: simple and safe, validated tests fof health problems which, if identified at an early stage, can be. treated or managed so as to improve the outcome?

We already have national agreement that screening for phenylketonuria and hypothyroidism at birth are wortto while. Guidelines are provided when to take the blood, and? there are standard methods, with checks, for carrying oub these tests. As a result nearly $100 \%$ screening for these्s conditions is now being achieved.

When it comes to other screening procedures, however for example, those for congenital dislocation of the hip $\overrightarrow{\mathrm{w}}$ undescended testes, vision, and hearing-we have ne national agreement other than perhaps the fact that the firse two should be tested for at birth. What should happen later ?o And how precisely should the tests be done? If wise peoples can gather together and produce guidelines on immunisation' should they not also gather together and do the same for these् screening procedures?

The concept of clinical freedom is totally inappropriate ing the provision of preventive measures, for these specifia screening methods have an optimal technique and an optimaP age for their performance. By failing to define these, tese them, and teach the methods, we are not only doing the children a dangerous disservice but also wasting time anco thus all too scarce resources. Furthermore, in my opinion the delay in sorting out who does what among clinical medicap officers, health visitors, general practitioners, and coms munity paediatricians results from the failure of the repre? sentatives of these groups to come together to work out theif common ground. Once a basic national programme of screening has been worked out each district can then decide for itself the best way to organise its services. An excellene initiative of this kind - ahead of any national programme-is. described at $\mathrm{p} 258$.

The handbook produced by the Council of Europe on Child Health Surveillance states": "High quality surveillancè programmes can be developed only if research becomes an obligation." This view is echoed in the report from a workingo group of the World Health Organisation, which states ${ }^{3}$. "Preschool screening has not yet been adequately evaluated? This evaluation should have high priority. At present, suchs screening should perhaps be limited to the surveillance of hearing and vision.... As a number of countries in the Region have determined that annual examinations of alf schoolchildren by a physician are not efficacious and mase create a large number of false positives and iatrogenie problems, and have consequently reduced this form of monitoring to very few examinations, this trend should be promoted."

Nationally organised research may seem both costly an $\omega_{5}^{\top}$ time consuming - but not doing the research is in the long run infinitely more costly.

Once a basic screening programme has been agreed-eveno if this consists only of four techniques-screening for congenital dislocation of the hip and undescended testes ando testing vision and hearing - then nationally agreed teaching programmes of videos, questionnaires, booklets, and so on, could quickly be developed by the DHSS commissioning the work from a few specified districts. Efficient screening is, 
however, only part of child health surveillance: it must be supported by effective services for making a final diagnosis and for the subsequent treatment and management of the identified impairment before it becomes a handicap.

Next - why do we in the health services hold parents in such poor esteem? Parents are responsible for their children's health 365 days a year and on the whole do it very well-they deal with $90 \%$ of their children's illnesses without going near the health services, ${ }^{4}$ and yet we seem to refuse to show them respect for this by allowing them to keep their own children's health and development records. We cry "But they'll lose them," yet French parents of all social classes do not lose them and nor do New Zealand parents or those African populations where they are used. Furthermore, some studies suggest that using parent observations, both on their children's vision and hearing, greatly aids in the identification of problems. ${ }^{5}$

The second clinical task of the community child health services is the management, support, and treatment of children with special needs and their families. Unless the parents themseles can communicate the special needs of their own child to whoever looks after the child-teacher, grandmother, playschool leader, or childminder-then the medical services have failed. If we have not informed the parents in such a way that they understand their child's needs and can transfer this information to others, then something is wrong. This is another reason for making the parents the holders of the health record on each child as an added resource for the parents to use when informing all these people.

Though the overall incidence of handicap has remained much the same (except perhaps with the increased incidence of diabetes and a small but important group coming from intensive care baby units), the prevalence at specific ages is increasing because children with handicaps are living longer. The technological means of helping handicapped children are improving enormously, giving them the chance of better mobility and better communication. The Education Act 1981 is moving children with special needs out of special schools into either special units within mainstream schools, mainstream schools themselves, or a combination of both. This has often increased the time spent travelling by those offering therapeutic support, increased the number of other professionals that the medical services have to deal with, and increased the need for specialised equipment, all on a great many different sites. ${ }^{6}$

None of these three factors has been allowed for in the government's financing of the health services; as a result, in many districts the facilities for handicapped children are grossly underfunded. This has led in some cases to bitter battles over budgets by people who used to be colleagues with amicable relationships. The trend for families to resort to litigation to provide resources for the care of an individual handicapped child must reflect, in part, the present lack of adequate funding of facilities. In practical terms the current lack of resources ought to lead to more cooperation than ever between social services, education, and the health services to provide for children, whether they be handicapped, abused, or normal. Without such cooperation much time is wasted passing requests for equipment or professional support from once service budget to another, rather than trying to pool the meagre resources that are available.

Finally, policies for all children can be correctly formulated only if we have systems which allow us some pieces of basic information, on a whole population basis. This has been begun with the production of certain performance indicators, but we need to go further. If we are to run efficient services in terms both of benefits for the child population we serve and of money provided for the NHS then we must have information systems which tell us about trends, about age groups, about degrees of disability, about the ages at which children are identified, who identifies them, and the final diagnosis.

Just as essentially, we must also be able accurately to record what services children with special needs require and what services we can actually provide. And if what we are able to provide falls further and further short of what is required this may then be accurately recorded and advertised.

Without these developemnts the wranglings will go on, morale among all those concerned in the care of children will get even worse, the community child health services will deteriorate, and the most vulnerable section of our population will suffer.

AIDAN MACFARLANE

Consultant Community Paediatrician,

Community Health Offices,

Redcliffe Infirmary,

Oxford OX2 6HE

1 Macfarlane A, Pillay U. Who does what, and how much in the preschool child health services in

England? Br Med J 1984;289:851-2.
2 Vanderboorde J, ed. European Committee 1985, child health surveillance. Strasbourg: Council of Europe Publication Section, 1985, and London: HMSO, 1985.

3 World Health Organisation European Working Group. Today's health-tomorrow's wealth, new perspectives in prevention in childhood. Summary report, Kiev, 21-25 October 1985. Geneva: World Health Organisation, 1985. (ICP/MCH 102/m04(s)6981F.)

4 Spenser N. Parents' recognition of the ill child. In: Macfarlane A, ed. Progress in child health vol 1. Edinburgh: Churchill Livingstone, 1984:100-12.

5 Hall S, Pugh A, Hall D. Vision screening in the under-5s. Br Med f 1982;285:1096-8.

6 Macfarlane A. The Education Act 1981. Br Med f 1985;290:1848-9.

\section{Bladder dysfunction in progressive autonomic failure}

When disturbances of continence or micturition occur in middle age the most likely diagnosis in men is prostatic obstruction and in women stress urinary incontinence. In either of these circumstances the patient's symptoms may be completely resolved by appropriate surgical intervention. It is important to recognise, however, that a much less common disease exists which mimics these disorders in its presentation but responds poorly to surgery. Characterised by primary degeneration of autonomic neurones, it is termed progressive autonomic failure. Often this disorder occurs in conjunction with more widespread degeneration of the central nervous system-multiple system atrophy.

Progressive autonomic failure was first described under the title "idiopathic orthostatic hypotension" by Bradbury and Eggleston, ${ }^{1}$ though it was Shy and Drager who first noted in a necropsy study of two cases that autonomic failure may be linked with a degeneration of the intermediolateral column cells in the spinal cord. ${ }^{2}$ In the cases they described there was a widespread disturbance of nervous function, which they attributed to selective degeneration in other parts of the brain including the corpus striatum, the substantia nigra, and the pontine nuclei. The condition was originally known as the Shy-Drager syndrome, but as neurological features they did not recognise have been added it is now usually known as "progressive autonomic failure with multiple system atrophy." Recently it has been recognised 